\title{
Consumo e Digestibilidades Aparentes Total e Parcial, de Nutrientes, em Bovinos Recebendo Rações Contendo Feno de Capim-Tifton 85 de Diferentes Idades de Rebrota ${ }^{1}$

\author{
Karina Guimarães Ribeiro², Rasmo Garcia ${ }^{3}$, Odilon Gomes Pereira ${ }^{3}$, Sebastião de Campos \\ Valadares Filho ${ }^{3}$, Paulo Roberto Cecon ${ }^{4}$
}

\begin{abstract}
RESUMO - Avaliaram-se o consumo, a digestibilidade aparente total e as digestibilidades aparentes ruminal e intestinal de rações contendo feno de capim-tifton 85 (Cynodon spp.) de diferentes idades de rebrota, em bovinos. Utilizaram-se quatro animais, fistulados no rúmen e abomaso, distribuídos em quadrado latino 4 x 4 . Todas as rações continham $60 \%$ de volumoso e $40 \%$ de concentrado. O volumoso era constituído de feno de capim-tifton 85 de 28, 35, 42 e 56 dias de rebrota, e o concentrado continha somente fubá de milho e mistura mineral. Os consumos de matéria seca (MS), matéria orgânica (MO), proteína bruta (PB), fibra em detergente neutro (FDN), carboidratos totais (CHOS), nutrientes digestíveis totais (NDT), matéria orgânica digestível (MOD) e carboidratos digestíveis totais (CHOSD) foram influenciados pela idade do feno na ração, com valores máximos estimados em 5,$81 ; 5,51 ; 0,71 ; 3,4 ; 4,69 ; 4,17 ; 4,04$; e $3,5 \mathrm{~kg} / \mathrm{dia}$, respectivamente, às idades de 40,6; 40,6; 32,6; 41,5; 42,2; 37,6; 37,7; e 39 dias. As digestibilidades aparentes totais da FDN e dos CHOS totais reduziram-se 0,33 e 0,21 unidades percentuais, para cada dia de avanço na idade do feno na ração, variando de 68,5 a $59,1 \%$ e de 76,9 a $71,1 \%$, respectivamente. As digestibilidades aparentes totais da MS, MO, PB e EE não foram influenciadas pela idade do feno na ração, apresentando valores médios de 70,9; 72,6; 60,0; e 74,4\%, respectivamente. As digestibilidades aparentes ruminal e intestinal dos nutrientes também não foram influenciadas pela idade do feno na ração.
\end{abstract}

Palavras-chave: carboidratos, fibra em detergente neutro, matéria orgânica digestível, matéria seca, proteína bruta

\section{Intake and Total and Partial Apparent Digestibilities of Nutrients, in Cattle Fed Diets Containing Tifton 85 bermudagrass Hays at Different Regrowth Ages}

\begin{abstract}
The intake, total apparent digestibility and ruminal and intestinal apparent digestibilities of diets containing tifton 85 bermudagrass hays (Cynodon spp.) at different regrowth ages were evaluated with cattle. Four rumen and abomasum fistulated steers were allotted in a $4 \times 4$ Latin square. All diets consisted in 0 to 40 forage to concentrate ratio. The forage was consisted in Tifton 85 bermudagrass hay of 28, 35, 42 and 56 days of age, and the concentrate contained corn meal and mineral mix. The intakes of dry matter (DM), organic matter (OM), crude protein (CP), neutral detergent fiber (NDT) total carbohydrates (CHOS), total digestible nutrients (TDN), digestible organic matter (DOM) and total digestible carbohydrates (TDC) were affected by the hay age in the diet, with maximum estimated values of $5.81 ; 5.51 ; 0.71 ; 3.4 ; 4.69 ; 4.17 ; 4.04$ and $3.5 \mathrm{~kg}$ /day, respectively, at the ages of $40.6 ; 40.6 ; 32.6 ; 41.5 ; 42.2 ; 37.6$; 37.7 and 39 days. The apparent digestibilities of NDF and total CHOS decreased 0.33 and 0.21 percent units for each day of hay age, ranged from 68.5 to 59.1 and 76.9 to $71.1 \%$, respectively. The digestibilities of DM, OM, CP and EE were not affected by the hay age, and presented mean values of $70.9 ; 72.6 ; 60.0$ and $74.4 \%$, respectively. The ruminal and intestinal nutrient digestibilities were not affected by the hay age in the diet.
\end{abstract}

Key Words: carbohydrates, neutral detergent fiber, digestible organic matter, dry matter, crude protein

\section{Introdução}

Os sistemas de produção de carne e, ou, leite, a pasto, são submetidos a períodos de safra e entressafra, decorrentes das condições climáticas intrínsecas das estações, com variações dependentes da região e do ano de produção. Assim, uma opção de manejo é o armazenamento do alimento excedente durante o período chuvoso, para ser ofertado aos animais, como fonte suplementar, em períodos de escassez de pasto. A fenação constitui uma prática viável, em muitas situações. Para isso, a gramínea a ser fenada deve apresentar alguns requisitos como a alta produção de matéria seca, elevado valor nutritivo e rápida taxa de secagem, entre outros.

O capim-tifton 85 (Cynodon spp.) é um híbrido selecionado na Geórgia, Estados Unidos, por BURTON et al. (1993), que apresenta característi-

\footnotetext{
1 Parte da tese de Doutorado do primeiro autor, parcialmente financiada pela FAPEMIG (CAG 2316/96).

2 Professora da FESURV, Rio Verde - GO. Campus Universitário, Cx. Postal 104, Cep 75901-970, Rio Verde, GO. E-mail: karina@fesurv.br

3 Professores do DZO/UFV, Viçosa - MG, Bolsitas do CNPq. E.mail: odilon@ufv.br

4 Professor do DPI/UFV, Viçosa - MG, Bolsista do CNPq.
} 
cas favoráveis tanto para a produção de feno quanto para o pastejo. HILL et al. (1993) verificaram produção de $1160 \mathrm{~kg} / \mathrm{ha} /$ ano de peso vivo e ganho médio diário de $0,67 \mathrm{~kg}$, em novilhos pastejando o capim-tifton 85 com teores de PB, FDN e coeficientes de DIVMS variando de 11,4 a $15,6 \%, 71,4$ a $75,4 \%$ e 57,3 a $61,9 \%$, respectivamente.

WEST et al. (1995), trabalhando com vacas leiteiras recebendo rações com $41,2 \%$ de concentrado, $13,8 \%$ de caroço de algodão, fornecido inteiro, e $45 \%$ de volumoso, contendo 15 ou $30 \%$ de feno de capimtifton 85 ou feno de alfafa, e o restante silagem de milho, observaram mais alto consumo de MS para as rações contendo feno de alfafa ou mais baixo nível de feno nas rações, o que, segundo esses autores, pode ser atribuído aos mais baixos teores de FDN dessas rações. Também foi observado que a digestibilidade da FDN foi mais alta nas rações contendo feno de capim-tifton 85 , em relação àquelas contendo feno de alfafa $(58,4$ x 39,3\%), o que pode refletir boas características de digestão da parede celular do capimtifton 85, fator importante para vacas leiteiras ou outras categorias animais de alta produtividade.

O consumo é uma das variáveis mais importantes que afetam o desempenho animal, sendo influenciado por características do animal, do alimento e das condições de alimentação. Segundo VAN SOEST (1965), o consumo é inversamente correlacionado ao teor de parede celular acima de 55-65\%. O teor de matéria seca indigerível na dieta também foi citado como o maior impedimento ao consumo de matéria seca pelos ruminantes (CONRAD, 1966). O consumo é inversamente relacionado ao teor de parede celular indigerível, que, ocupando espaço no trato gastrintestinal, reduz o consumo. Além da indigestibilidade da fibra, as taxas de digestão da fibra e de passagem pelo trato gastrointestinal são altas e positivamente correlacionadas com o consumo (MERTENS e ELY, 1979). Em muitas situações, o consumoépositivamente correlacionadoà digestibilidade da dieta (WALDO e JORGENSEN, 1981).

O estádio de maturidade da planta forrageira à colheita influencia o seu valor nutritivo mais do que qualquer outro fator. À medida que a planta cresce e se desenvolve, os teores de lignina e FDN aumentam, enquanto o teor de $\mathrm{PB}$ e a digestibilidade da matéria seca são reduzidos. As plantas forrageiras maduras não são tão consumidas quanto as mais jovens, provavelmente devido às mudanças estruturais e bromatológicas com o avanço da maturidade, que decresce a taxa de digestão, retarda a passagem e, conseqüentemente, reduz o consumo. Portanto, é relevante o conhecimento do momento de colheita, pois a forragem de melhor qualidade certamente promoverá maiores consumo e performance animal.

HILL et al. (1997a), trabalhando com fenos de três cultivares de Cynodon (coastal, tifton 78 e tifton 85 ) e duas idades de corte ( 28 e 42 dias), ofertados a novilhos de $279 \mathrm{~kg}$, verificaram que o consumo de MS não foi afetado pelos tratamentos, registrando-se consumo médio de 5,3 kg/dia. Os fenos de coastal, tifton 78 e tifton 85 , com teores protéicos entre 7 e $10,6 \%$ e FDN entre 78,6 e $83,8 \%$, apresentaram coeficientes de digestibilidade de MO, PB e FDN de $47,8,51,0$ e $54,3 \%$; de $36,0,34,4$ e $33,2 \%$; e de 51,3 ; 55,4 e $61,3 \%$, respectivamente. As digestibilidades dos nutrientes foram reduzidas com o aumento da idade das plantas ao corte, para todos os cultivares.

Em trabalho com fenos de capim-tifton 85 e capimcoastal, colhidos com 21,35 e 49 dias de idade, ofertados a novilhos em crescimento, Mandebvu et al., 1998, citados por HILL et al. (1998), verificaram mais alto consumo de $\mathrm{MO}(4,7 \times 4,3 \mathrm{~kg} / \mathrm{dia})$ e mais baixo consumo de PB $(0,64$ x 0,70 kg/dia) em fenos de gramíneas colhidas com 49 dias, relativamente aos de gramíneas com 21 dias de idade. O consumo médio de FDN foi $3,4 \mathrm{~kg} / \mathrm{dia}$. As digestibilidades da $\mathrm{MO}$ e PB foram semelhantes em fenos de gramíneas de diferentes idades, apresentando-se, em média, 56,6 e 59,1\%, respectivamente, enquanto a digestibilidade da FDN foi mais baixa em fenos de gramíneas com 49 dias $(58,6 \%)$, em relação àquelas com 21 dias de idade $(64,1 \%)$.

O estudo da inclusão de feno de capim-tifton 85 em rações para vacas leiteiras revelou que a digestão da FDN das rações melhorou, à medida que a porcentagem de feno de capim-tifton 85 aumentou, refletindo a alta digestibilidade da FDN do capim-tifton 85 (WEST et al., 1998). De fato, os resultados de HATFIELD et al. (1997) indicaram que a melhoria da digestibilidade e desempenho animal, com a utilização do capim-tifton 85 , pode ser atribuída aos mais baixos teores de lignina e polissacarídeos interligados, além de mais baixas ocorrências de ferulatos éter ligados à lignina encontrados nessa gramínea.

Verifica-se que o capim-tifton 85 é uma forragem de elevada qualidade, quando bem manejado, podendo ser utilizado desde novilhos em crescimento (HILL et al., 1993, 1997a, b) até vacas em lactação (WEST et al., 1995; 1998), com as devidas suplementações em nutrientes, conforme o ganho a ser obtido.

A digestibilidade parcial dos nutrientes de um alimento é determinada para melhor conhecimento 
Rev. bras. zootec.

do processo digestivo nos diferentes compartimentos do trato gastrointestinal, o que permite melhor avaliação do potencial do alimento. Vários trabalhos apresentam a relevância da determinação desses parâmetros (CARVALHO et al., 1996; LADEIRA et al., 1998; DIAS, 1999).

Objetivou-se, com este trabalho, avaliar o consumo, a digestibilidade aparente total e as digestibilidades aparentes ruminal e intestinal de nutrientes, em bovinos recebendo dietas contendo fenos de capim-tifton 85 de diferentes idades de rebrota.

\section{Material e Métodos}

O experimento foi realizado no Laboratório de Animais do Departamento de Zootecnia da Universidade Federal de Viçosa, no período de agosto a outubro de 1997. Foram utilizados quatro animais zebu, não-castrados, com peso médio inicial de $340 \mathrm{~kg}$, fistulados no rúmen e no abomaso, distribuídos em um delineamento em quadrado latino 4 x 4 . Os animais foram mantidos em baias individuais cobertas, de $2 \times 2,5 \mathrm{~m}$, com comedouros e bebedouros circulares de alvenaria, sendo pesados no início e ao final de cada período experimental.

As rações contendo feno de capim-tifton 85 de diferentes idades de rebrota foram balanceadas segundo o NRC (1996), com proporção de volumoso:concentrado de 60:40, de modo que a energia metabolizável das rações atendesse aos requerimentos dos animais para o ganho diário de $1,0 \mathrm{~kg}$.

Na Tabela 1 é apresentada a composição bromatológica dos fenos e do concentrado. O feno de capim-tifton 85 foi produzido com 28, 35, 42 e 56 dias de rebrota, após uma adubação com $75 \mathrm{~kg} /$ ha de $\mathrm{N}$, na forma de sulfato de amônio, e $60 \mathrm{~kg} / \mathrm{ha} \mathrm{de} \mathrm{K}_{2} \mathrm{O}$, como cloreto de potássio, no município de Tupaciguara, na região do Triângulo Mineiro. Na Tabela 2 encontra-se a composição percentual do concentrado usado nas quatro rações.

Consta da Tabela 3 a composição das rações experimentais. A ração foi fornecida duas vezes ao dia, às $7 \mathrm{~h} 30 \mathrm{e}$ às $15 \mathrm{~h}$, exceto quando se coletaram amostras para determinação do $\mathrm{pH}$ e da concentração de amônia, quando se forneceu toda a ração pela manhã. A quantidade de ração fornecida diariamente foi calculada permitindo aproximadamente $10 \%$ de sobras.

Cada período experimental teve a duração de 18 dias, sendo dez dias para adaptação dos animais às rações e oito dias para coletas, dos quais quatro dias foram destinados a coletas de digesta de abomaso e fezes, para determinação das digestibilidades totais e parciais; um dia, à coleta de urina, para determinação da perda de $\mathrm{N}$ urinário; dois dias, à coleta de digesta ruminal, para determinação da taxa de passagem, sendo coletados também, durante o $7^{\circ}$ dia de coletas, aproximadamente $200 \mathrm{~mL}$ de fluido ruminal, para determinação do $\mathrm{pH}$ e da concentração de $\mathrm{N}-\mathrm{NH}_{3}$. No oitavo dia, foram coletadas amostras de fluido ruminal para o isolamento de bactérias.

As coletas de digesta do abomaso e fezes foram realizadas duas vezes ao dia, durante quatro dias, às $7 \mathrm{~h} 30 \mathrm{e} 13 \mathrm{~h} 30$, no $1^{\circ} \mathrm{dia}$, às $9 \mathrm{~h}$ e $15 \mathrm{~h}$, no $2^{\circ} \mathrm{dia}$, às $10 \mathrm{~h} 30$ e $16 \mathrm{~h} 30$, no $3^{\circ} \mathrm{dia}$, e às $12 \mathrm{~h}$ e $18 \mathrm{~h}$, no $4^{\circ}$ dia (ZINN e OWENS, 1993). As porções fecais, coletadas no mesmo dia, foram armazenadas juntas, de modo que, ao final de cada período experimental, foram obtidas quatro amostras de fezes e oito de digestas de abomaso, por animal, as quais foram armazenados em freezer a aproximadamente $-15^{\circ} \mathrm{C}$.

Tabela 1 - Teores médios de matéria seca (MS), matéria orgânica (MO), proteína bruta (PB), extrato etéreo (EE) e fibra em detergente neutro (FDN) do feno de capim-tifton 85 de diferentes idades de rebrota e do concentrado na ração

Table 1 - Dry matter (DM), organic matter (OM), crude protein (CP), ether extract (EE) and neutral detergent fiber (NDF) contents of the concentrate and Tifton 85 bermudagrass hay, at different regrowth ages

\begin{tabular}{|c|c|c|c|c|c|}
\hline Idade do feno (dias) & MS & MO & PB & $\mathrm{EE}$ & FDN \\
\hline Hay age (days) & $D M$ & $O M$ & $C P$ & $E E$ & $N D F$ \\
\hline & & \multicolumn{4}{|c|}{$\begin{array}{c}\% \text { na MS } \\
\% D M\end{array}$} \\
\hline 28 & 85 & 92,9 & 16,4 & 1,35 & 78,8 \\
\hline 35 & 86 & 92,6 & 15,5 & 1,67 & 78,7 \\
\hline 42 & 86 & 93,3 & 14,3 & 1,38 & 79,9 \\
\hline 56 & 85 & 92,4 & 11,3 & 1,04 & 81,3 \\
\hline $\begin{array}{l}\text { Concentrado } \\
\text { Concentrate }^{*}\end{array}$ & 88 & 97,3 & 8,3 & 3,55 & 15,0 \\
\hline
\end{tabular}

\footnotetext{
* Concentrado contendo fubá de milho e mistura mineral.

* Concentrate containing ground corn and mineral mixture.
} 
Tabela 2 - Composição percentual da ração concentrada, expressa na base da matéria natural

Table 2 - Ingredient composition of the concentrate diet, as fed basis

\begin{tabular}{lc}
\hline $\begin{array}{l}\text { Ingredientes } \\
\text { Ingredients }\end{array}$ & $\begin{array}{c}\text { Composição (\%) } \\
\text { Composition (\%) }\end{array}$ \\
\hline Fubá de milho (Ground corn) & 98,3 \\
Mistura mineral (Mineral mixture) & 1,7 \\
\hline${ }^{1}$ Calcário (35,1\%); cloreto de sódio $(32,4 \%)$; fosfato bicálcico $(30,3 \%) ;$ \\
sulfato de zinco (1,7\%); sulfato de cobre (0,5\%); sulfato de cobalto \\
(0,006\%).
\end{tabular}

O consumo das rações foi mensurado por meio da pesagem do ofertado e das sobras, coletando-se amostras diárias da ração ofertada e das sobras, por tratamento, por animal, em cada período de coletas. Para determinação da excreção de MS fecal, utilizou-se o indicador óxido crômico, ministrado, via fístula ruminal, em duas porções diárias de $10 \mathrm{~g}$ cada, durante os sete dias finais do período de adaptação e os quatro dias do período de coletas, exceto à tarde do último dia.

$\mathrm{Na}$ ocasião do processamento, as amostras foram retiradas do freezer ao final da tarde e, no dia seguinte, levadas para uma estufa com ventilação forçada a $60-65^{\circ} \mathrm{C}$, por 72 horas. As amostras de digestas de abomaso foram pesadas, antes e após a retirada da estufa, para determinação da porcentagem de amostra seca ao ar (ASA). Após a secagem, todas as amostras foram moídas, em moinho tipo Wiley, utilizando-se peneira de $1 \mathrm{~mm}$ de diâmetro de poros. Aproximadamente $10 \mathrm{~g}$ de cada amostra seca de digesta de abomaso foram reunidos para formar uma amostra composta por animal, em cada período, sendo acondicionadas em recipientes de vidro para posteriores análises laboratoriais.
Os teores de MS, MO, PB, EE e FDN, nas amostras dos alimentos fornecidos (feno e concentrado), sobras, digestas de abomaso e fezes, além de $\mathrm{Cr}$, nas duas últimas amostras, foram determinados segundo metodologias descritas por SILVA (1990).

Os carboidratos totais (CHOS) foram obtidos por meio da equação, citada por SNIFFEN et al. (1992): CHOS $(\% \mathrm{MS})=100-(\% \mathrm{~PB}+\% \mathrm{EE}+\% \mathrm{CINZAS})$. Para o cálculo do consumo de nutrientes digestíveis totais (NDTc), utilizou-se a equação, citada por SNIFFEN et al. (1992): $\mathrm{NDTc}=(\mathrm{PBc}-\mathrm{PBf})+2,25(\mathrm{EEc}-\mathrm{EEf})$ $+(\mathrm{CHOSc}-\mathrm{CHOSf})$, que representa os consumos e excreções fecais de proteína bruta (PBc e PBf), extrato etéreo (EEc e EEf) e carboidratos totais (CHOSc e CHOSf), respectivamente. A concentração de nutrientes digestíveis totais (NDT) foi calculada pela equação, citada por SNIFFEN et al. (1992): \%NDT $=($ NDTc/ MSc) x 100, em que MSc representa o consumo de matéria seca. A concentração de energia metabolizável (EM), em Mcal $/ \mathrm{kg}$, foi obtida pela equação: $\mathrm{EM}=\%$ NDT $\times 4,409 \times 0,82$ (SNIFFEN et al., 1992).

Os dados de consumo e digestibilidades aparentes totais, ruminais e intestinais foram submetidos às análises de variância e regressão, em função da idade do feno contido na ração $(28,35,42$ e 56 dias), utilizando-se o programa SAEG versão 7.0. Os modelos foram selecionados utilizando-se como critérios a significância do coeficiente de regressão, pelo teste "t", a 1, 5 e $10 \%$ de significância, o coeficiente de determinação e o conhecimento do comportamento do fenômeno estudado.

\section{Resultados e Discussão}

Os resultados referentes aos consumos médios dos nutrientes, e suas respectivas equações de regressão, encontram-se na Tabela 4.

Tabela 3 - Teores médios de matéria seca (MS), matéria orgânica (MO), proteína bruta (PB), extrato etéreo (EE), carboidratos totais (CHOS), fibra em detergente neutro (FDN), nutrientes digestíveis totais (NDT) e energia metabolizável (EM), em Mcal $/ \mathrm{kg}$, de rações contendo feno de capim-tifton 85 de diferentes idades de rebrota

Table 3 - Mean contents of dry matter (DM), organic matter (OM), crude protein (CP), ether extract (EE), total carbohydrate (TC), neutral detergent fiber (NDF), total digestible nutrients (TDN) and metabolizable energy (ME), in Mcal/kg, of diets containing Tifton 85 bermudagrass hay at different regrowth ages

\begin{tabular}{|c|c|c|c|c|c|c|c|c|}
\hline Idade do feno na & MS & $\mathrm{MO}$ & PB & $\mathrm{EE}$ & CHOS & FDN & NDT & $\mathrm{EM}$ \\
\hline Ração (dias) & $D M$ & $O M$ & $C P$ & $E E$ & $T C$ & $N D F$ & $T D N$ & $M E$ \\
\hline $\begin{array}{l}\text { Hay age on the diet } \\
(\text { days })\end{array}$ & \multicolumn{8}{|c|}{$\begin{array}{c}\% \text { na } \mathrm{MS} \\
(\% \text { in } D M)\end{array}$} \\
\hline 28 & 86,2 & 94,7 & 13,2 & 2,23 & 79,3 & 53,3 & 73,7 & 2,66 \\
\hline 35 & 86,8 & 94,5 & 12,6 & 2,42 & 79,5 & 53,2 & 70,9 & 2,56 \\
\hline 42 & 86,8 & 94,9 & 11,9 & 2,25 & 80,7 & 53,9 & 72,9 & 2,64 \\
\hline 56 & 86,2 & 94,4 & 10,1 & 2,04 & 82,3 & 54,8 & 67,5 & 2,44 \\
\hline
\end{tabular}


Rev. bras. zootec.

Tabela 4 - Consumos médios de matéria seca (MS), matéria orgânica (MO), proteína bruta (PB), extrato etéreo (EE), fibra em detergente neutro (FDN), carboidratos totais (CHOS), nutrientes digestíveis totais (NDT), matéria orgânica digestível (MOD) e carboidratos totais digestíveis (CHOSD), equações de regressão, ajustadas em função das idades de rebrota (I) do feno na ração $\left(28,35,42\right.$ e 56 dias), e coeficientes de determinação $\left(R^{2}\right)$

Table 4 - Intakes of dry matter (DM), organic matter (OM), crude protein (CP), ether extract (EE), neutral detergent fiber (NDF), total carbohydrates (TC), total digestible nutrients (TDN), digestible organic matter (DOM) and digestible total carbohydrate (DTC) and fitted regression equations, in function of the hay regrowth ages (I) $(28,35,42$ and 56 days) on the diets and the determination coefficient $\left(R^{2}\right)$

\begin{tabular}{|c|c|c|c|c|c|c|}
\hline \multirow[t]{2}{*}{ Item } & \multicolumn{4}{|c|}{$\begin{array}{l}\text { Idade do feno na ração (dias) } \\
\text { Hay age on the diet (days) }\end{array}$} & \multirow[t]{2}{*}{$\begin{array}{l}\text { Equação de regressão } \\
\text { Regression equation }\end{array}$} & \multirow[t]{2}{*}{$\mathrm{R}^{2}$} \\
\hline & 28 & 35 & 42 & 56 & & \\
\hline \multicolumn{7}{|c|}{ Consumo (kg/dia) } \\
\hline $\operatorname{MS}(D M)$ & 5,39 & 5,85 & 5,72 & 5,27 & $\hat{\mathrm{Y}}=1,9294+0,1908 * * * \mathrm{I}-0,002347 * * * \mathrm{I}^{2}$ & 0,90 \\
\hline $\mathrm{MO}(O M)$ & 5,12 & 5,54 & 5,44 & 4,99 & $\hat{\mathrm{Y}}=1,7742+0,1841 * * * \mathrm{I}-0,002266 * * * \mathrm{I}^{2}$ & 0,92 \\
\hline $\mathrm{PB}(C P)$ & 0,69 & 0,72 & 0,66 & 0,52 & $\hat{\hat{Y}}=0,3416+0,02258 * \mathrm{I}-0,0003459 * * \mathrm{I}^{2}$ & 0,98 \\
\hline $\mathrm{EE}$ & 0,13 & 0,15 & 0,14 & 0,11 & $\hat{\mathrm{Y}}=0,136$ & \\
\hline $\mathrm{FDN}(N D F)$ & 3,09 & 3,38 & 3,37 & 3,06 & $\hat{\hat{Y}}=0,574+0,1364 * I-0,001645 * I^{2}$ & 0,98 \\
\hline $\mathrm{CT}(T C)$ & 4,29 & 4,66 & 4,63 & 4,35 & $\hat{\mathrm{Y}}=1,4237+0,1544 * * * \mathrm{I}-0,001827 * * * \mathrm{I}^{2}$ & 0,92 \\
\hline NDT (TDN) & 3,98 & 4,18 & 4,11 & 3,51 & $\hat{\mathrm{Y}}=1,3562+0,1494 * * * \mathrm{I}-0,001984 * * * \mathrm{I}^{2}$ & 0,99 \\
\hline $\operatorname{MOD}(D O M)$ & 3,85 & 4,04 & 3,98 & 3,40 & $\hat{\hat{Y}}=1,3375+0,1432 * * * I-0,001899 * \mathrm{I}^{2}$ & 0,99 \\
\hline $\operatorname{CTD}(D T C)$ & 3,30 & 3,49 & 3,47 & 3,03 & $\hat{\mathrm{Y}}=1,0007+0,1283 * * * \mathrm{I}-0,001645 * \mathrm{I}^{2}$ & 0,99 \\
\hline \multicolumn{7}{|c|}{ Consumo (kg/dia) } \\
\hline $\operatorname{MS}(D M)$ & 1,56 & 1,67 & 1,66 & 1,55 & $\hat{\mathrm{Y}}=0,7065+0,0468 * * * \mathrm{I}-0,0005659 * * * \mathrm{I}^{2}$ & 0,93 \\
\hline $\mathrm{MO}(O M)$ & 1,49 & 1,59 & 1,58 & 1,47 & $\hat{\mathrm{Y}}=1,53$ & \\
\hline $\mathrm{PB}(C P)$ & 0,20 & 0,20 & 0,19 & 0,15 & $\hat{\hat{\mathrm{Y}}}=0,1302+0,004787 * \mathrm{I}-0,0000777 * * \mathrm{I}^{2}$ & 0,99 \\
\hline $\mathrm{FDN}(N D F)$ & 0,89 & 0,96 & 0,97 & 0,90 & $\hat{\mathrm{Y}}=0,2402+0,0349 * \mathrm{I}-0,000414 * \mathrm{I}^{2}$ & 0,98 \\
\hline \multicolumn{7}{|c|}{ Consumo (kg/dia) } \\
\hline $\operatorname{MS}(D M)$ & 67,1 & 72,0 & 71,2 & 66,4 & $\hat{\mathrm{Y}}=28,15+2,1305 * * * \mathrm{I}-0,02588 * * * \mathrm{I}^{2}$ & 0,92 \\
\hline $\mathrm{MO}(O M)$ & 63,8 & 68,2 & 67,8 & 62,9 & $\hat{\mathrm{Y}}=25,94+2,0652 * * * \mathrm{I}-0,02512 * * * \mathrm{I}^{2}$ & 0,95 \\
\hline $\mathrm{PB}(C P)$ & 8,7 & 8,9 & 8,3 & 6,6 & $\hat{\mathrm{Y}}=5,08+0,2337 * * \mathrm{I}-0,003687 * * \mathrm{I}^{2}$ & 0,99 \\
\hline $\mathrm{FDN}(N D F)$ & 38,2 & 41,5 & 41,7 & 38,5 & $\hat{\hat{Y}}=9,9725+1,5184 * I-0,01796 * I^{2}$ & 0,97 \\
\hline
\end{tabular}

${ }^{*},{ }^{* *},{ }^{* * *}$, significativo a 5,1 e $10 \%$ de probabilidade, pelo teste t.

${ }^{*}{ }^{* *}$ and ${ }^{* * *}$, significant at 1,5 and $10 \%$ of probability, respectively, by $t$ test.

Observaram-se comportamentos quadráticos dos consumos de matéria seca e matéria orgânica (kg/dia, \%PV e g/kg $\left.{ }^{0,75}\right)$, em função da idade do feno incluído nas dietas, exceto para o consumo de MO (\%PV), que apresentou valor médio de $1,53 \% \mathrm{PV}$. Estimaram-se consumos máximos de MS de $5,81 \mathrm{~kg} / \mathrm{dia}$, $1,67 \% \mathrm{PV}$ e $72 \mathrm{~g} / \mathrm{kg}^{0,75}$, quando as rações continham feno de capim-tifton 85 de 40,6; 41,3; e 41,2 dias de rebrota, respectivamente. Estimaram-se máximos consumos de MO de 5,51 kg/dia e 68,39 g/ $/ \mathrm{kg}^{0,75}$, quando as rações continham feno de 40,6 e 41,1 dias, respectivamente.

Em experimento com ovinos, utilizando-se, como fonte única, os mesmos fenos usados no presente experimento, ATAÍDE JR. et al. (2000) também encontraram comportamento quadrático para a ingestão de feno em função da idade de rebrota, estimando máximo consumo para feno com 39 dias de rebrota. Por outro lado, em ensaio de desempenho com bovinos da raça nelore, utilizando as mesmas rações do presente estudo, exceto aquela contendo feno de 28 dias, ATAÍDE JR. et al. (2001) verificaram comportamento linear decrescente para o consumo de MS, com reduções de $0,037 \mathrm{~kg} / \mathrm{dia}$, com o avanço da idade do feno incluído na ração. Mandebvu et al., 1998, citados por HILL et al. (1998), verificaram mais altos consumos em novilhos recebendo, como fonte única, fenos de capim-tifton 85 ou capimcoastal de plantas colhidas com 49 dias de idade do que com 21 ou 35 dias.

Os consumos de matéria seca e matéria orgânica foram aquém dos esperados, provavelmente devido ao estresse provocado pela metodologia de coletas realizada nesse tipo de experimento, uma vez que o consumo de animais nelore, em confinamento, recebendo rações semelhantes, incluindo fenos de 35 a 56 
dias de rebrota, variou de 8,13 a 7,26 kg/dia (ATAÍDE JR. et al., 2001).

Os consumos de PB, expressos em kg/dia, \%PV e $\mathrm{g} / \mathrm{kg}^{0,75}$, apresentaram efeito quadrático da idade do feno na ração, estimando-se consumos máximos de PB de $0,71 \mathrm{~kg} / \mathrm{dia}, 0,20 \% \mathrm{PV}$ e $8,8 \mathrm{~g} / \mathrm{kg}^{0,75}$, com a inclusão de fenos de 32,6; 30,8; e 31,7 dias de idade na ração, respectivamente, o que está consistente com os elevados teores protéicos das rações contendo fenos mais jovens. ATAÍDE JR. et al. (2001) verificaram reduções de $0,014 \mathrm{~kg} / \mathrm{dia}$, no consumo de $\mathrm{PB}$, em rações contendo feno de capim-tifton 85 de 35 a 56 dias de idade. O consumo de EE, no presente trabalho, não foi influenciado pela idade do feno na ração, sendo $136 \mathrm{~g} / \mathrm{dia}$, em média.

Os consumos de FDN também foram influenciados pela idade do feno na ração, apresentando resposta quadrática, estimando-se consumos máximos de $3,4 \mathrm{~kg} / \mathrm{dia}, 0,98 \% \mathrm{PV}$ e $42,1 \mathrm{~g} / \mathrm{kg}^{0,75}$, em dietas contendo feno de 41,$5 ; 42,1$; e 42,3 dias, o que se explica pelo maior consumo de MS a essas idades, visto que o teor de FDN foi similar entre as rações.

Os consumos de CHOS, NDT, MOD e CTD também apresentaram comportamentos quadráticos, encontrando-se consumos máximos de 4,69; 4,17; 4,04; e $3,50 \mathrm{~kg} /$ dia, respectivamente, em rações contendo fenos de 42,2; 37,6; 37,7; e 39 dias, respectivamente. Segundo MERTENS (1994), o desempenho do animal é função direta do consumo de matéria seca digerível. No presente experimento, rações contendo feno de capim-tifton 85 , de 37,7 dias de rebrota, proporcionaram o mais alto consumo de MO digerível.

Os coeficientes de digestibilidade aparente total encontram-se na Tabela 5. Não se encontrou efeito da idade do feno incluído na ração sobre os coeficientes de digestibilidade aparente total de MS, MO, PB e EE, que apresentaram valores médios de 70,9; 72,$6 ; 60,0 ;$ e 74,4\%, respectivamente. Os coeficientes de digestibilidade aparente total da FDN e dos CHOS foram influenciados pela idade do feno incluído na ração, estimando-se reduções de 0,33 e 0,21 unidades percentuais por dia, respectivamente, em rações contendo feno com 28 a 56 dias de rebrota. Assim, as digestibilidades da FDN e dos CHOS variaram de 68,5 a $59,1 \%$ e de 76,9 a $71,1 \%$, respectivamente.

DIAS (1999), trabalhando com rações variando de 25 a $75 \%$ de concentrados, encontrou que as digestibilidades aparentes totais da MS, MO, PB, EE, FDN e CHOS, para a ração contendo $62,5 \%$ de feno de capim-coastcross, foram 53,8; 56,3, 50,8; 63,1; 56,9; e 32,4\%, respectivamente. Assim, embora a formulação dos concentrados seja diferente, verifica-se que os coeficientes de digestibilidade aparente total, para rações contendo $60 \%$ de feno de capim-tifton 85 , encontrados no presente trabalho, foram mais elevados do que nas rações contendo feno de capim-coastcross.

A redução na digestibilidade dos nutrientes com o avanço da idade da planta é relatada, em diferentes espécies de plantas forrageiras, por VAN SOEST (1994). Para o capim-tifton 85 e capim-coastal fornecidos como fonte única, na forma de feno, Mandebvu et al., 1998, citados por HILL et al. (1998), verificaram reduções nas digestões da FDN e da FDA, de 64,1 para $58,6 \%$ e de 58,7 para $53,1 \%$, respectivamente, em plantas colhidas com 21 e 49 dias de idade, embora não tenham encontrado influência da idade de rebrota dos fenos sobre as digestões da MS e MO.

Em experimento com carneiros, ATAÍDE JR. et al. (2000), utilizando fenos de capim-tifton 85 semelhantes aos do presente experimento, verificaram decréscimos lineares para as digestibilidades dos nutrientes, com reduções de aproximadamente 0,16 ; 0,38 ; e 0,17 unidades percentuais, para os coeficientes de digestibilidade da MS, PB e FDN, com o aumento da idade de rebrota do feno de 28 a 56 dias. Já em experimentos com bovinos, utilizando-se as mesmas dietas do presente experimento, exceto o feno de 28 dias de rebrota, não se verificou influência da idade do feno sobre os coeficientes de digestibilidades de MS, PB, EE, FDN e CHOS (ATAÍDE JR. et al., 2001).

De modo geral, no presente trabalho, a ração contendo feno de 56 dias de idade apresentou tendência de mais baixos coeficientes de digestibilidade dos nutrientes, o que pode ser atribuído ao mais baixo teor protéico e de nutrientes digestíveis totais, além do mais alto teor de FDN indigerível do feno incluído nessa ração, como observado por HENRIQUES et al. (1998). Entretanto, verifica-se que os altos coeficientes de digestibilidade dos nutrientes encontrados para as rações contendo feno de capim-tifton 85 corrobora com vários trabalhos incluindo essa gramínea, em rações para vacas de leite e para novilhos de corte (HILL et al, 1996, 1998; WEST et al., 1995, 1998).

Não se encontrou efeito da idade do feno incluído na ração sobre a digestibilidade ruminal aparente dos nutrientes, observando-se valores médios de 59,6; 67,$8 ;-4,36 ;-30,5 ; 95,5 ;$ e $79,8 \%$ para os coeficientes de digestibilidade ruminal aparente de MS, MO, PB, EE, FDN e CHOS, respectivamente (Tabela 5). 
Rev. bras. zootec.

Observa-se que os coeficientes de digestibilidade ruminal da PB apresentaram valores negativos com o aumento da idade do feno incluído na ração, sendo que somente a dieta contendo feno de 28 dias de idade proporcionou valor médio positivo para a digestibilidade ruminal aparente da $\mathrm{PB}$, de 7,3\%, o que indica que houve pequena perda de $\mathrm{N}$ sob a forma de amônia no rúmen, pois o esperado seria um coeficiente de digestibilidade próximo de zero. Os valores médios negativos, encontrados para rações contendo fenos de 35, 42 e 56 dias de idade, indicam pequeno déficit de proteína degradada no rúmen (PDR) na ração, pois chegou ao abomaso maior quantidade de proteína do que foi ingerida. Ressalta-se que o teor protéico das dietas variou de 13,2 a 10,1\%, para dietas com inclusão de fenos de 28 a 56 dias de rebrota.

Os coeficientes de digestibilidade ruminal negativos para o extrato etéreo devem-se à ocorrência de síntese de lipídeos microbianos no rúmen, o que faz com que cheguem mais lipídeos no abomaso do que a quantidade ingerida do mesmo, conforme verificado por LADEIRA (1998) e DIAS (1999).

Trabalhando com a inclusão de concentrados na ração, DIAS (1999) encontrou, para rações contendo $62,5 \%$ de feno de capim-coastcross, coeficientes de digestibilidade aparente ruminal de 57,5; 73,8;-24,8; $-30,4 ; 138,3$; e $56,9 \%$, respectivamente, para MS, MO, PB, EE, FDN e CHOS.

Os coeficientes de digestibilidade intestinal aparente da MS, MO, PB, EE, FDN e CHOS, no presente estudo, também não foram influenciados pela idade do feno na ração, apresentando valores médios de 40,$4 ; 32,2 ; 61,3 ; 80,2 ; 4,5 ;$ e $20,2 \%$, respectivamente (Tabela 5).

Da proporção digerida no trato digestivo total, a maioria da digestão da FDN (95,5\%, em média) e aproximadamente $80 \%$ dos carboidratos totais ocorreram no rúmen.

Tabela 5 - Digestibilidades aparentes médias totais de matéria seca (MS), matéria orgânica (MO), proteína bruta (PB), extrato etéreo (EE), fibra em detergente neutro (FDN) e carboidratos totais (CT), equações de regressão em função das idades de rebrota (I) do feno na ração e coeficientes de determinação $\left(\mathrm{r}^{2}\right)$

Table 5 - Mean apparent digestibilities of dry matter (DM), organic matter (OM), crude protein (CP), ether extract (EE), neutral detergent fiber (NDF) and total carbohydrates (TC), fitted regression equations on the hay regrowth ages (I) $(28,35,42$ and 56 days) on the diets and coefficient of determination $\left(r^{2}\right)$

\begin{tabular}{|c|c|c|c|c|c|c|}
\hline \multirow[t]{2}{*}{ Item } & \multicolumn{4}{|c|}{$\begin{array}{c}\text { Idade do feno na ração (dias) } \\
\text { Hay age on the diet (days) }\end{array}$} & \multirow[t]{2}{*}{$\begin{array}{l}\text { Equação de regressão } \\
\text { Regression equation }\end{array}$} & \multirow[t]{2}{*}{$\mathrm{r}^{2}$} \\
\hline & 28 & 35 & 42 & 56 & & \\
\hline \multicolumn{7}{|c|}{ Digestibilidade total $(\%)$} \\
\hline \multicolumn{7}{|c|}{ Total apparent digestibility $(\%)$} \\
\hline $\operatorname{MS}(D M)$ & 73,3 & 70,6 & 72,3 & 67,3 & $\hat{\mathrm{Y}}=70,9$ & \\
\hline $\mathrm{MO}(O M)$ & 75,1 & 72,3 & 74,1 & 69,0 & $\hat{\mathrm{Y}}=72,6$ & \\
\hline $\mathrm{PB}(C P)$ & 64,5 & 59,0 & 61,4 & 55,0 & $\hat{\mathrm{Y}}=60,0$ & \\
\hline $\mathrm{EE}$ & 74,6 & 73,7 & 75,7 & 73,7 & $\hat{\mathrm{Y}}=74,4$ & \\
\hline $\mathrm{FDN}(N D F)$ & 67,9 & 65,0 & 66,6 & 58,0 & $\hat{\mathrm{Y}}=77,8369-0,334316^{*} \mathrm{I}$ & 0,82 \\
\hline $\mathrm{CT}(T C)$ & 76,9 & 74,4 & 75,8 & 70,5 & $\hat{\mathrm{Y}}=82,698-0,206286 * * * \mathrm{I}$ & 0,79 \\
\hline \multicolumn{7}{|c|}{ Digestibilidade total $(\%)$} \\
\hline \multicolumn{7}{|c|}{ Total apparent digestibility (\%) } \\
\hline $\operatorname{MS}(D M)$ & 63,1 & 57,0 & 55,4 & 63,0 & $\hat{\mathrm{Y}}=59,6$ & \\
\hline $\mathrm{MO}(O M)$ & 70,9 & 65,9 & 63,4 & 70,9 & $\hat{\hat{Y}}=67,8$ & \\
\hline $\mathrm{PB}(C P)$ & 7,3 & $-5,1$ & $-10,0$ & $-9,6$ & $\hat{\mathrm{Y}}=-4,46$ & \\
\hline $\mathrm{EE}$ & $-25,1$ & $-31,5$ & $-33,1$ & $-32,2$ & $\hat{\hat{Y}}=-30,5$ & \\
\hline FDN $(N D F)$ & 97,2 & 94,2 & 93,7 & 96,9 & $\hat{\hat{Y}}=95,5$ & \\
\hline $\mathrm{CT}(T C)$ & 82,1 & 78,6 & 76,0 & 82,5 & $\hat{\mathrm{Y}}=79,8$ & \\
\hline \multicolumn{7}{|c|}{ Digestibilidade total (\%) } \\
\hline \multicolumn{7}{|c|}{ Total apparent digestibility $(\%)$} \\
\hline $\operatorname{MS}(D M)$ & 36,9 & 43,0 & 44,6 & 37,0 & $\hat{\mathrm{Y}}=40,4$ & \\
\hline $\mathrm{MO}(O M)$ & 29,1 & 34,1 & 36,6 & 29,1 & $\hat{\hat{Y}}=32,2$ & \\
\hline $\mathrm{PB}(C P)$ & 61,2 & 60,6 & 64,9 & 58,7 & $\hat{\mathrm{Y}}=61,3$ & \\
\hline $\mathrm{EE}$ & 79,5 & 79,9 & 81,5 & 80,0 & $\hat{\mathrm{Y}}=80,2$ & \\
\hline $\mathrm{FDN}_{(N D F)}$ & 2,8 & 5,8 & 6,3 & 3,1 & $\hat{\hat{Y}}=4,5$ & \\
\hline $\mathrm{CT}(T C)$ & 17,9 & 21,4 & 24,0 & 17,5 & $\hat{\mathrm{Y}}=20,2$ & \\
\hline
\end{tabular}




\section{Conclusões}

A inclusão de feno de capim-tifton 85 com 42 dias de idade, nas rações, promoveu consumo máximo dos nutrientes, excetuando-se de extrato etéreo.

As digestibilidades aparentes totais de MS, MO, $\mathrm{PB}$ e EE não foram influenciadas pela idade do feno na ração, enquanto as digestibilidades aparentes totais da FDN e dos CHOS decresceram 0,33 e 0,21 unidades percentuais, por dia de aumento na idade do feno na ração, respectivamente.

As digestibilidades aparentes ruminais e intestinais não foram influenciadas pela idade do feno na ração.

\section{Agradecimento}

Aos irmãos Marcos e César Prado, proprietários da Fazendas Prado, em Tupaciguara, MG, pelo fornecimento dos fenos utilizados neste trabalho.

\section{Referências Bibliográficas}

ATAÍDE JR., J.R., PEREIRA, O.G., GARCIA, R. et al. 2000. Valor nutritivo do feno de capim-tifton 85 (Cynodon spp.) em diferentes idades de rebrota, em ovinos. Rev. bras. zootec., 29(6):2193-2199 (suplemento 2).

ATAÍDE JR., J.R., PEREIRA, O.G., VALADARES FILHO, S.C. et al. 2001. Consumo, digestibilidade e desempenho de novilhos alimentados com rações à base de feno de capimtifton 85, em diferentes idades de rebrota. Rev. bras. zootec., $30(1): 215-221$.

BURTON, G.W., GATES, R.N., HILL, G.M. 1993. Registration of "tifton 85" bermudagrass. Crop Sci., 33(3):644-645.

CARVALHO, A.U., VALADARES FILHO, S.C., COELHO DA SILVA, J.F. et al. Efeito dos níveis de concentrados sobre a digestão parcial dos nutrientes em zebuínos. In: REUNIÃO ANUAL DA SOCIEDADE BRASILEIRA DE ZOOTECNIA, 33, Fortaleza, 1996. Anais... Fortaleza: SBZ, 1996. p.64-66.

CONRAD, H.R. 1966. Symposium on factors influencing the voluntary intake of herbage by ruminants: physiological and physical factors limiting feed intake. J. Anim. Sci., 25:227-235.

DIAS, H.L.C. Consumo, digestibilidade e eficiências microbiana em novilhos $F 1$ limousin $x$ nelore alimentados com dietas contendo cinco níveis de concentrado. Viçosa, MG, UFV, 1999. 76p. Tese (Mestrado em Zootecnia), Universidade Federal de Viçosa, 1999.

HENRIQUES, L.T., PEREIRA, O.G., VALADARES FILHO, S.C. et al. Degradabilidade "in situ" da matéria seca e da fibra em detergente neutro do feno de tifton-85 (Cynodon spp.), em quatro idades de rebrota. In: REUNIÃO ANUAL DA SOCIEDADE BRASILEIRA DE ZOOTECNIA, 35, Botucatu, 1998. Anais....Botucatu, SBZ, 1998. p.570-572.

HATFIELD, R.D., MANDEBVU, P., WEST, J. 1997. A comparison of tifton 85 and coastal bermudagrass cell walls. (http://www.dfrc.ars.usda.gov./Research_Sumaries/1997).

HILL, G.M., GATES, R.N., BURTON, G.W. 1993. Forage quality and grazing steer performance from tifton 85 and tifton 78 bermudagrass pastures. J. Anim. Sci., 71(12):3219-3225.

HILL, G.M., GATES, R.N., WEST, J.W. et al. Tifton 85 bermudagrass utilization in beef, dairy, and hay production.
In: WORKSHOP SOBRE O POTENCIAL FORRAGEIRO DO GÊNERO CYNODON, 1996, Juiz de Fora. Anais... Juiz de Fora: EMBRAPA - CNPGL, 1996. p. 139-150.

HILL, G.M., GATES, R.N., WEST, J.W. et al. Pesquisa com capim bermuda cv. Tifton 85 em ensaios de pastejo e de digestibilidade de feno com bovinos. In: PEIXOTO, A.M.; MOURA, J.C.; FARIA, V.P. SIMPÓSIO DO MANEJO DE PASTAGENS DE TIFTON, COAST-CROSS E ESTRELA, 1998, Piracicaba. Anais... Piracicaba: ESALQ, 1998. p. 7-22.

HILL, G.M., GATES, R.N., WEST, J.W. et al. 1997a. Bermudagrass cultivar maturity effects on hay digestibility in steers. J. Anim. Sci., 75:201.

HILL, G.M., GATES, R.N., WEST, J.W. et al. 1997b. Consumption and digestibility of Coastal, tifton 78, and tifton 85 hays harvested at two maturity stages when fed to steers. (http://www.ads.uga.edu/annrpt/1997/97_031.htm).

LADEIRA, M.M., VALADARES FILHO, S.C., LEÃO, M.I. et al. Dietas contendo diferentes níveis de concentrado em novilhos nelore: digestibilidade aparente parcial. In: REUNIÃO ANUAL DA SOCIEDADE BRASILEIRA DE ZOOTECNIA, 35, Botucatu, 1998. Anais... Botucatu, SBZ, 1998. p.579-581.

MERTENS, D.R. Análise da fibra e sua utilização na avaliação e formulação de rações. In: SIMPÓSIO INTERNACIONAL DE RUMINANTES, REUNIÃO ANUAL DA SOCIEDADE BRASILEIRA DE ZOOTECNIA, 29, Lavras, 1992. Anais... Lavras, SBZ, 1992. p.188-219.

MERTENS, D.R. 1994. Regulation of forage intake. In: FAHEY JR., G.C., COLLINS, M., MERTENS, D.R., MOSER, L.E. (Eds). Forage quality, evaluation and utilization. Madison, Wisconsin: ASA-CSSA-SSSA. p.450-493.

MERTENS, D.R., ELY, L.O. 1979. A dynamic model of fiber digestion and passage in the ruminant for evaluating forage quality. J. Anim. Sci., 49(4):1085-1095.

NATIONAL RESEARCH COUNCIL - NRC. 1996. Nutrient requirements of beef cattle. 7.ed. Washington, D.C.: National Academy. 242p.

SILVA, D.J. 1990. Análise de alimentos (Métodos químicos e biológicos). Viçosa: UFV. 165p.

SNIFFEN, C.J., O'CONNOR, J.D., VAN SOEST, P.J. et al. 1992. A net carbohydrate and protein system for evaluating cattle diets: II. Carbohydrate and protein availability. J. Anim. Sci., 70(11):3562-3577.

VAN SOEST, P.J. 1965. Symposium on factors influencing the voluntary intake of herbage by ruminants: Voluntary intake relation to chemical composition and digestibility. J. Anim. Sci., 24(3):834-844

VAN SOEST, P.J. 1994. Nutritional ecology of the ruminant. Ithaca, New York: Cornell. 476p.

WALDO, D.R., JORGENSEN, N.S. 1981. Forages for high animal production: nutritional factors and effects of conservation. J. Dairy Sci., 64:1207-1229.

WEST, J.W., MANDEBVU, P., HILL, G.M. et al. 1998. Intake, milk yield, and digestion by dairy cows fed diets with incresing fiber content from bermudagrass hay or silage. J. Dairy Sci., 81:1599-1607.

WEST, J.W., MATHIS, M.J., HILL, G.M. et al. 1995. Effects of dietary forage source and fiber content on intake and lactational performance of dairy cows. (http://www.ads.uga.edu/annrpt/1995/95_186.htm).

ZINN, R.A., OWENS, F.N. 1993. Ruminal escape protein for lightweight feedlot calves. J. Anim. Sci., 71:1677-1687.

Recebido em: 16/06/00

Aceito em: 31/10/00 